\title{
The Effect of a Suggested In-service Teacher Training Program Based on MALL Applications on Developing EFL Students' Vocabulary Acquisition
}

\author{
Mohamed Ali Mohamed Kassem \\ Faculty of Education in the New Valley, Assiut University, Egypt
}

\begin{abstract}
Recently, Mobile Assisted Language Learning (MALL) has received much attention as a means to improve the performance of students in all language aspects. Learning vocabulary is not an exception as many applications have been designed to foster students' vocabulary acquisition. However, little attention has been paid to the preparation of teachers who should be aware of and competent in using such applications in order to attain the intended educational objectives. Consequently, the present study sought to train ten EFL secondary school teachers on the use of some MALL vocabulary applications and to investigate the effect of the teachers' use of such applications on their students' vocabulary acquisition. The training program entailed the use of four outstanding vocabulary learning applications: Quizlet, Digital Vocabulary Notebook, Digital Video Games and Online Dictionaries. A pre-post vocabulary test and an observation checklist were designed and implemented to measure the effect of the suggested training program. Results of the study indicated (1) the effectiveness of the suggested in-service teacher training program as teachers successfully integrated these applications in their vocabulary instruction and (2) a significant improvement in the students' vocabulary acquisition as a result of using MALL applications. It was recommended to provide teachers with an adequate training on the use of MALL technology to enable them to exploit the potentialities of such new applications and, eventually, to improve the students' vocabulary acquisition.
\end{abstract}

Index Terms-MALL, quizlet, digital vocabulary notebook, digital games, online dictionaries, vocabulary acquisition

\section{INTRODUCTION}

Vocabulary is an indispensable component of language learning that has received much attention in all educational settings as it fosters the development of all language skills and significantly affects students' achievement and progress in content-area courses (Nam, 2010). In addition, having adequate vocabulary is a prerequisite for successful communication (Baleghizadeh \& Ashoori, 2011). However, many EFL students consider vocabulary the most problematic area of language learning and a real obstacle that threatens their comprehension (Silverman \& Hines, 2009). Therefore, exploring various approaches to support students' vocabulary acquisition has become a focus of several studies in recent years. In this regard, integrating MALL in vocabulary instruction proves to be a promising approach (Azabdaftari \& Mozaheb, 2012; McLean, Hogg \& Rush, 2013).

In response to the fast-growing tendency to incorporate technology in educational settings and the wide spread of portable digital devices, much interest in utilizing MALL in EFL classrooms has been raised to satisfy students' needs and to cope up with educational innovations. According to Hockly (2013), the future tends to me more mobile, and it is teachers' duty to shape teaching practices in a way that incarnates this tendency. MALL is defined as the use of portable electronic devices such as smartphones and tablets to support language learning (Valarmathi, 2011). Consequently, many researchers have been attracted to integrate MALL technology in EFL classrooms to benefit from its potentialities and to address a wide range of problems. Fisher and Baird (2007) maintain that MALL provides instructors with an ideal tool for promoting active learning, collaboration and innovation among university students who are uncooperative and unmotivated. Romero et al (2010) emphasize the effectiveness of using MALL in (1) providing students with several opportunities to practice what they have learned outside the classroom, (2) developing all language skills, and (3) enabling students to work independently and to get immediate corrective feedback at the same time. Moreover, using MALL effectively creates authentic learning environment that involves learners in a learning experience that goes beyond the classroom walls (Al Shehri, 2011).

The success of MALL in language teaching and learning depends largely on teachers who assume the responsibility of integrating these applications in their classrooms (Vota, 2011). Therefore, teachers need to be trained in the use of MALL applications effectively to enrich their teaching activities and to satisfy their students' needs. Weinberger (2011) emphasizes the importance of teacher training claiming that the failure of almost all initiatives to utilize technology in language classrooms is due to teachers' lack of adequate technological skills and as a result technology becomes a 
burden and fails to achieve the educational objectives. In this regard, Norazah et al. (2010) highlight the negative impact of using technology ineffectively on students' learning. Therefore, providing sufficient and efficient pedagogical training is essential to guarantee the success of integrating MALL in classroom practices.

Although the curriculum and educational policy makers urge teachers to integrate MALL in their teaching practices, no adequate training on the use of handheld devices in language instruction is found. Al Sahli (2014) mentioned that the teachers' lack of technological knowledge and skills was the main challenge she faced in the implantation of her study. Teachers were not able to use online tools. Consequently, a training session aimed at qualifying teachers to use online tools in teaching was conducted. Similarly, Al Malihi (2015) reported that providing adequate in-service training on how to integrate MALL in classroom represented the top priority of 114 Saudi English teachers who participated in a needs analysis survey. Moreover, Djoub (2016) conducted a study to find out the obstacles that hinder English teachers from integrating MALL in their teaching practices. The results indicated that teachers' reluctance to use MALL was due to the lack of appropriate training. Training teachers through workshops or in-service programs was recommended. Therefore, the present study aims at training EFL teachers on the use of some MALL vocabulary learning applications and investigating the effect of using such applications on the students' vocabulary acquisition.

\section{A. Context of the Problem}

It was observed that the majority of the students who apply to join the Department of English at Prince Sattam University, KSA, suffer from poor vocabulary as indicated by their low scores in the admission/acceptance test. In addition, teachers reported that insufficient vocabulary repertoire is the biggest obstacle that students face in language learning. This observation is in accordance with a number of studies that asserted the students' lack of appropriate vocabulary needed for successful verbal and non-verbal communication (Khrisat \& Mahmoud, 2013; Al Sahli, 2014). This motivated the researcher to investigate the status-quo of vocabulary instruction in secondary schools. Therefore, twenty EFL secondary stage teachers were interviewed and observed while teaching vocabulary. The results indicated that (1) the traditional method of teaching vocabulary was used to provide students with literal meanings of new words mostly in the students' mother tongue, (2) no sufficient time was devoted for vocabulary reinforcement as class time was limited, and (3) absolute absence of MALL technology as teachers highlighted the fact that they are not aware of such applications as they graduated ten years back before launching these new innovations. Further investigation revealed that most English teachers graduated from College of Arts with inadequate information about teaching methodology in general and educational technology in particular (Al-Seghayer, 2011). In addition, no in-service training programs were conducted to equip them with up-to-date knowledge regarding new technological applications and innovative practices related to vocabulary teaching. It can be inferred that the students' real weaknesses in vocabulary acquisition may be attributed to the prevailing traditional teaching method that relies on a meaningless repetition of target vocabulary and a direct translation into the students' mother tongue with a complete absence of modern technology despite its availability in the Saudi educational context. Therefore, training teachers on the use of MALL vocabulary learning applications could present an alternative approach to support students' vocabulary acquisition.

\section{B. Statement of the Problem}

Secondary stage students in Al Kharj province show real weaknesses in vocabulary acquisition. This may be attributed to the use of the traditional method which does not permit effective integration of technology. Hence, the current study aimed at designing a training program to raise teachers' awareness and use of some MALL vocabulary learning applications and investigating the effect of using these applications on the students' vocabulary acquisition.

\section{Questions of the Study}

The present study sought to answer the following two questions:

1- What is the effect of implementing a suggested in-service teacher training program based on some MALL vocabulary learning applications on EFL teachers' use of such applications?

2- What is the effect of using MALL vocabulary learning applications on developing EFL students' vocabulary acquisition?

\section{Significance of the Study}

The present study is critically significant as it aims at: (1) designing an effective in-service teacher training program that aims at raising EFL teachers' awareness and use of MALL applications in vocabulary instruction, (2) exploring new methods for promoting EFL students' vocabulary acquisition, (3) presenting a framework of a training program that can be used to train teachers in other language skills, and (4) meeting the new trends in education that call for supporting lifelong learning, fostering independent learners and reducing the cost of the learning process via a wise use of technology.

\section{REVIEW OF LITERATURE}

\section{A. MALL and Vocabulary Acquisition}


Vocabulary acquisition has been considered a fundamental prerequisite for successful language learning. Therefore, several studies have been conducted to explore the potentiality of MALL in fostering students' vocabulary acquisition. Saran et al (2008) pinpointed the great potentiality of MALL in creating a successful learning environment through its unique features of mobility, reachability, and personalization of learning. Therefore, they conducted a study in which multimedia messages were used to help students to learn new vocabulary. The multimedia messages enabled the teachers to provide the students with definitions, examples, pronunciation and visual representations of new vocabulary. In addition, multimedia messages were utilized to test students' comprehension. The study recommended the use of multimedia messages in teaching and testing vocabulary. Similarly, Saeidi and Mozaheb (2012) confirmed the positive impact of using MALL on EFL university students' vocabulary acquisition compared to other teaching strategies such as traditional flashcards.

Hashemi and Abbasi (2013) conducted a study to investigate the impact of using mobile phones on EFL learners' vocabulary retention. One hundred eighty high school students participated in the study. The results indicated a significant improvement in terms of students' vocabulary retention. In addition, much attention was given to the presentation of new words features which led to an improvement in students' vocabulary memorization. Furthermore, Al Sahli (2014) investigated the impact of using online tools such as games, You Tube and digital storytelling on developing vocabulary achievement of Saudi secondary stage students. Al Sahli asserted the ineffectiveness of the traditional teaching method and recommended the integration of online applications as students' vocabulary was improved as a result of using such applications.

Reviewing the previous studies indicated that training teachers, who assume the responsibility of integrating MALL applications in vocabulary instruction, was neglected. Teacher's ability to use MALL effectively was not sufficiently considered. In addition, challenges and difficulties that teachers faced were not mentioned. Considering teachers' roles, readiness and ability to integrate MALL in vocabulary instruction has distinguished the present study from earlier studies.

\section{B. Pros and Challenges of MALL}

A review of the relevant studies revealed that MALL possesses some unique features that drive both teachers and learners to use its applications in and out language classroom. Mobility and ubiquity characterize MALL and enable learners to use the portable devices at anytime and anywhere (Zaki \& Yunus, 2015). Being connected wirelessly to internet is another feature that facilitates the use of MALL applications and enables students to study outside the classroom (Sharples, Taylor \& Vavoula, 2005). Interactivity is another feature that enables students to interact and communicate regardless of time and place. Moreover, students can access and retrieve information easily and this fosters their learning process and helps them to work autonomously (Suneetha, 2013). MALL devices sustain students' privacy as they can monitor their learning progress without being worried about teachers' and colleagues' comments. Furthermore, being adaptable to individual and diverse learners provides the opportunity to personalize learning (Pachler, 2010). Finally, MALL suits the learning preferences of the $21^{\text {st }}$ century students who are described as "The App generation" (Gardner \& Davis, 2013). Thus, MALL has the potentiality to increase students' motivation and creates a supporting learning environment (Ally et al, 2007).

Despite the aforementioned advantages of using MALL in language classrooms, it faces a number of challenges and limitations. The possibility of students' distraction by play games, text messages and checking social websites worries teachers (Kuznekoff \& Titsworth, 2013). The cost of the device could represent another challenge especially in developing countries. However, this is not the case in KSA in which all students have smart phones and an internet connection is provided for free in schools and universities. Another difficulty is associated with the screen size as it tends to be quite small and thus may hurt students when used for a long period of time. Larsen-Freeman and Anderson (2011) added other challenges such as limited battery life and memory capacity. However, it is well recognized that the benefits of MALL outweigh such limitations.

\section{MALL Vocabulary Learning Applications}

Recently, the use of web-based flashcard programs such as Quizlet has become a popular tool used by second/foreign language teachers to foster their students' vocabulary learning. Quizlet is an interactive website that enables its users to retrieve the meaning of words using flashcard sets and a number of learning tools. According to recent statistics, Quizlet has more than one million registered users and eighty million visitors all over the world (Quizlet, 2014). Students can easily access Quizlet without creating an account. However, students are obliged to register if they would like to create their own word lists and enjoy extra features such as image uploading and voice recording. Three reasons may justify the popularity of web-based flashcard programs: (1) increasing students' vocabulary size and tracking their progress, (2) introducing new vocabulary using multimedia, and (3) enabling students to study at any time in any place as long as they are connected to internet (McLean, Hogg \& Rush, 2013).

Many studies have indicated the effectiveness of Quizlet in enhancing students' vocabulary learning. Davie and Hilber (2015) conducted a survey to investigate the attitudes of undergraduate engineering students towards the use of Quizlet application in learning vocabulary. Sixty-eight students participated in the study and responded to a questionnaire. Their performance was measured via a vocabulary test. The results showed an improvement in students' vocabulary acquisition. In addition, the students showed a real interest in using Quizlet as they believed that it was a 
convenient and enjoyable learning tool. Investigating long-term benefits and conducting the study on a larger scale over a longer period of time were recommended by the aforementioned study. Similarly, Dizon (2016) confirmed the significant impact of using Quizlet on developing English vocabulary of nine Japanese students who studied Coxhead's (2001) academic vocabulary list over the course of ten weeks.

Digital Vocabulary Notebook (DVN) is another popular MALL vocabulary learning application that was developed to replace the traditional paper notebook and to improve its effectiveness through the advantages of technology. Apparently, using DVN brings many advantages to vocabulary learning as it (1) enables students to review, edit and organize their own vocabulary lists at their own convenience (Bazo, Rodriguez \& Fumero, 2016), (2) guides students through the process of learning vocabulary, (3) provides formative assessment as many self-assessment tests are available, (4) supports students' autonomy and (5) saves classroom precious time which can be devoted for practical activities that strengthen students' understanding and stimulate their use of target vocabulary. Moreover, being connected to the internet enables students to interact, through the web application, with their teachers and, hence, saving classroom time. On the other hand, teachers are able to monitor students' progress and to obtain valuable feedback which is used later on to identify the real needs and difficulties faced students. Consequently, teachers plan for carrying out some actions and activities to help students to address successfully such problems at an early stage. Walters (2009) conducted a study and concluded that DVN was proved to be effective in helping students to learn vocabulary faster and more efficient.

Recently, Digital Video Games (DVG) have been classified under the umbrella of MALL and gained much popularity among teachers who seek to utilize them to foster students' learning. Tsai and Fan (2013) maintain that game-based learning is a type of learning in which video games are integrated with education. In the domain of language learning, a distinction has been made between game-based and game-enhanced language learning. Reinhardt and Sykes (2012) mentioned that the main difference between the aforementioned two types lies in the fact that gamebased type is associated with those DVGs that are specifically tailored to achieve specific language learning outcomes whereas game-enhanced type is a commercial-off-the shelf DVGs that can be used in language classrooms.

A number of studies have sought to integrate DVGs in vocabulary instruction. Dehaan, Reed, and Kuwada (2010) investigated the impact of DVG on vocabulary recall of eighty Japanese university students who are majoring in computer science. They divided the students into two groups: players and watchers. The players were requested and given the chance to interact with the game whereas the watchers assumed the role of observer. The students were requested to memorize a number of lyrics without taking notes, stop the game, or resort to a dictionary. Then a vocabulary recall cloze test was used and the results showed that the watchers performed significantly better than the players who reported the difficulty of paying attention to the game and lyric memorization at the same time. Similarly, Histosugi and Hayashi (2014) investigated the impact of using DVGs on Japanese university students' affect and vocabulary learning. The results indicated the positive impact on students' affect and a significant improvement in vocabulary learning. Similar conclusions were asserted by Ebrahimzadeh (2017) who reported the effectiveness of DVGs in fostering students' vocabulary acquisition.

Online dictionaries, accessed through handheld devices, represent another type of MALL applications. Many studies have reported the effectiveness of using online dictionaries in learning vocabulary as indicated by the performance of students in post and delayed tests compared to students who do not have an access to a dictionary (Macaro, 2005). Generally speaking, dictionaries have been used to help students in accomplishing three goals: (1) comprehending spoken and written language through identifying the meaning of unknown words, (2) producing language through finding out the words that are needed for speaking, writing, and translation, and (3) increasing students' knowledge of words and how to use in different contexts (Nation, 2001). In the past, some teachers rejected the use of dictionary claiming that this will increase the cognitive load that affects negatively the reading comprehension and encouraged their students to use dictionaries as the last resort. They believed in the effectiveness of using contextual analysis to find out the meaning of unknown words. However, it proves to be hard to rely on the contextual clues only to identify the meaning (Laufer, 2003). The online dictionaries such as Dictionary.com, Merriam-Webster Dictionary, and The Free Dictionary have been found effective in decreasing the cognitive load and improving students' vocabulary acquisition as they enable students to access the meaning of words, etymology, sample sentences and pronunciation quickly and efficiently (Deng \& Trainin, 2015).

\section{MALL and Teacher Training Program}

Recent research has indicated three major areas that should be covered in any training program that aims at developing teachers' use of MALL applications: (1) technological knowledge that is related to the use and features of each application, (2) content knowledge that specifies the material and topics to be taught using the MALL applications, and (3) pedagogical knowledge denotes the activities to be used in class to integrate the MALL applications in the learning process (Mishra \& Koehler, 2006; Koshman, 2011). In addition, benefits and limitations of using handheld devices should be presented to trainees. The training program should provide teachers with an opportunity to practice a number of activities that would encourage students to use MALL applications effectively (Passey, 2010). Some of these activities are: (1) "Review and reflect" activity in which students download an image or a movie related to the idea presented in the lesson and reflect on the key aspects of the information and how to be implemented or used in a larger context, (2) "Think forward" activity aims at enabling students to prepare in advance the upcoming topics through 
downloading relevant material and discussing it via online applications or in class, (3) "Listen to my explanations" activity allows students to record their explanation of the lesson at home and to send it to their teacher to be evaluated and (4) "Tell me how I could improve this" activity encourages students to upload and share their work with others through MALL applications with the goal of improving the quality of their work based on the feedback they receive.

Lomine and Buckhingham (2009) proposed a practical framework for tailoring an effective in-service MALL Training program. They highlight three major points to be considered seriously prior to the integration of MALL applications: pedagogy, economics and technology. Pedagogy refers to the educational value of using such applications. Teachers should be aware of the learning outcome that the application may help students to achieve. Economics indicates the cost of utilizing MALL applications. Finally, technology considers the availability and practicality of applications. All the aforementioned aspects were considered in designing the suggested in-service training program.

Dashtestani (2014) affirmed the significance of training teachers on MALL as a prerequisite for launching such applications in language classrooms. Based on the results of a computer literacy questionnaire and a general computer literacy test, Dashtestani indicated that the majority of English teachers who participated in the study were not qualified to integrate MALL applications in their classes as they lack the fundamental knowledge and skills to deal with such applications. Three reasons were identified as major obstacles for using MALL: (1) absence of appropriate training whether in teacher education programs or in-service professional development, (2) inadequate support from educational authorities, and (3) the challenges related to the cost and the availability of handheld devices and technological infrastructure.

\section{METHOD}

\section{A. Sample of the Study}

Ten secondary stage teachers, from public schools in Al Kharj governorate, volunteered to participate in the training program that lasted for four weeks. An observation checklist was used to evaluate teachers' use of vocabulary learning applications. As for assessing the effect of teachers' use of vocabulary learning applications on developing their students' vocabulary acquisition, two hundred first secondary grade students were pre-and post-tested.

\section{B. Design of the Study}

Due to the nature of the study, one group pre-post test design was utilized in the present study. A vocabulary test was designed and administered on the students before and after the experiment.

\section{Instruments of the Study}

\section{The Suggested Teacher Training Program}

In order to raise the teachers' awareness and use of MALL vocabulary learning applications, a training program was proposed to present four widely-used applications: Quizlet, Digital Vocabulary Notebook, Digital Video Games and Online Dictionaries. A fundamental step in designing the suggested program was needs assessment. This step aimed at identifying the real training needs, points of strength and points of weaknesses to be addressed by the program. Therefore, semi-structured interviews were conducted with the teachers seeking to identify their knowledge of vocabulary learning applications, attitudes, and experience related to MALL. Results indicated mainly the teachers' insufficient knowledge of MALL applications and their reluctances to use such applications in teaching vocabulary.

Based on the needs assessment results, the objectives and content were assigned. The program included introduction and four units. The concept, definition, significance and common applications of MALL were presented in the introduction. Each unit provides trainees with enough information about one vocabulary application and the trainees were given the opportunities to practice individually or in groups. Introducing trainees to each application with enough explanation about its use in vocabulary instruction was carried out first. The technical features and educational values were addressed too. Then, trainees were requested to work individually or in groups carrying out some relevant activities such as using the applications to get the meaning of some words accompanied with illustrative examples. Trainees' use of vocabulary learning applications was highly stressed in the training program. Finally, trainees' awareness and use of the vocabulary learning applications were assessed through requesting them to answer a quiz by the end of each unit and observing their performance in their English language classrooms.

\section{Observation Checklist}

It was designed to assess the teachers' use of MALL applications in teaching vocabulary. Its final version included ten (10) statements. A five-point Likert Scale, ranging from 1 (strongly disagree) to 5 (strongly agree), was utilized to rate the teachers' use of MALL applications. The observation checklist was submitted to a panel of TEFL experts to decide its content and face validity. The panel's feedback was taken into consideration in formulating the final version of the checklist. Thus, it was an approved, validated and appropriate tool for measuring teachers' use of MALL vocabulary applications. The reliability of the checklist was assessed via the test-retest method. It was administered twice to a sample of five teachers who were excluded from the main sample of the study later on. Four weeks separated the two administrations. An Alpha Cronbach's correlation coefficient of (.88) was calculated. Moreover, an internal consistency reliability check was computed and it was found that the alpha coefficient for the checklist was (.90).

3. Vocabulary Acquisition Test (VAT) 
VAT was designed to assess the students' vocabulary acquisition before and after the intervention. The test was consisted of fifty multiple choice questions (MCQ) that represent the target vocabulary taught and practiced via MALL vocabulary learning applications. MCQ format is recommended by The Ministry of Education to test Grade 10 students' vocabulary acquisition. Each question receives a point. Thus, the maximum score for the test was fifty (50) points. Two EFL instructors volunteered to score students' answers. In order to assure the validity of the test, it was submitted to a jury of experts. All their comments and suggestions were taken into consideration in the final version of the test. Thus, the test was approved as a valid and appropriate tool for measuring the students' vocabulary acquisition. As for the reliability, a test re-test method was used to estimate the test reliability. The test was administered on a group of students who represented the target population. They were excluded from the sample of the study. After that, Pearson product moment correlation formula was used to estimate the coefficient of stability, $(\mathrm{r}=.78)$, of the test. This indicates that the test is reliable. The test was piloted and the optimal test time was calculated and found to be forty (40) minutes.

4. Procedures

The experiment started in the first semester of the academic year (2016-2017). The researcher started the training program with twelve teachers from public schools. Two teachers did not attend the first three sessions. Therefore, they were excluded from the sample of the study. Before starting the experiment, the researcher made sure that the schools are provided with an adequate internet service and it is available for teachers and students. The training program started with an orientation in which the general objectives, expectations, roles and procedures of the training program were presented.

After conducting the training program, teachers were requested to use MALL applications in teaching vocabulary throughout the second semester. The researcher was keen to attend several classes to observe the teachers' real performance and to evaluate the effectiveness of the training program. Teachers introduced and encouraged students to use the four vocabulary learning applications. In this respect, students were highly motivated to use these applications. In the beginning of the second semester, the pre-test of vocabulary acquisition was carried out on the sample of the study. Then, students spent fifteen weeks learning vocabulary via the MALL vocabulary learning applications. By the end of the semester, students were post- tested and the results were statistically analyzed using SPSS program.

\section{RESUlTS AND DisCUSSION}

\section{A. Results of the Observation Checklist}

Wilcoxon Signed-Ranks Test was used to compare the teachers' use of MALL applications before and after the training program. The results, displayed in Table 1, indicated that post-test ranks were statistically significantly higher than pre-test ranks $z=2.677, p<0.007$. Thus, it can be concluded that the suggested training program was effective in enhancing the teachers' use of MALL applications in vocabulary instruction.

TABLE 1.

WILCOXON SIGNED-RANKS TEST RESULTS

\begin{tabular}{|c|c|c|c|c|}
\hline \multirow{3}{*}{ Teacher's use of vocabulary apps. } & \multicolumn{2}{|l|}{ Mean Ranks } & \multirow{2}{*}{ (Z) } & \multirow{2}{*}{ Sig.(2-tailed) } \\
\hline & Negative Ranks & Positive ranks & & \\
\hline & 0.00 & 5.00 & -2.677 & 0.007 \\
\hline
\end{tabular}

\section{B. Results of the Vocabulary Acquisition Test}

A Paired-samples t-test was conducted to compare the mean scores of the students before and after the experiment. The results, displayed in Table 2, showed statistically significant difference in the students' scores for the pretest (M $=21.12, \mathrm{SD}=8.69)$ and for posttest $(\mathrm{M}=45.44, \mathrm{SD}=4.28) ; \mathrm{t}(199)=31.418, \mathrm{p}=0.01$ in favor of the post application. These findings affirmed the positive effect of using MALL vocabulary learning applications on developing the students' vocabulary acquisition.

TABLE 2.

PAIRED-SAMPLES T-TEST RESULTS

\begin{tabular}{|c|c|c|c|c|c|c|c|}
\hline & Yocabulary test & No & Mean & $\mathrm{SD}$ & tyalue & $\mathrm{df}$ & Sig (2-tailed) \\
\hline Pre & & \multirow{2}{*}{200} & 21.12 & 8.69 & \multirow{2}{*}{31.418} & \multirow{2}{*}{199} & \multirow{2}{*}{$0.01 *$} \\
\hline Post & & & 45.44 & 4.28 & & & \\
\hline
\end{tabular}

\section{Discussion}

Firstly, the obtained results affirmed the effectiveness of the suggested in-service training program in raising teachers' awareness and use of MALL applications as reflected in their responses and performance in teaching vocabulary. The success of the training program may be attributed to several reasons: (1) addressing a real need to integrate technology in teaching practices, (2) stressing the educational significance of using MALL in teaching vocabulary, (3) presenting the content in an interactive mode apart from the listening mode in which trainees stay passive, (4) providing various hands-on activities, and (5) providing instant technical support. 
Secondly, the results of the present study confirmed the positive impact of using MALL applications in improving students' vocabulary acquisition. These results are in congruence with those of other similar studies (Reinhardt \& Sykes, 2012; Ebrahimzadeh, 2017). Improvement in students' vocabulary acquisition may be attributed to the fact that using such applications outside the classroom enabled the students to be exposed greatly to the target words and increased their interaction with these words. In other words, the portability of vocabulary learning applications provided the students with a chance to access the target vocabulary from their preferred time and place. In addition, MALL applications succeeded to present the meaning of the new words using varied textual and visual means that attracted and motivated students to acquire words efficiently. This finding is consistent with Gee's (2003) multimodal principle that asserts the value of using diverse modalities in prompting students' vocabulary acquisition.

Moreover, results of the present study support the belief that MALL applications fit the learning styles of students in the $21^{\text {st }}$ century as they advocate learners' autonomy and massive use of technological innovations. Fostering students' autonomy enabled some students to overcome many motivational challenges. These applications created an interactive classroom in which students get and share information about meaning and usage of vocabulary spontaneously. Moreover, receiving instant feedback and varied examples enriched students' knowledge and fostered their vocabulary acquisition.

\section{CONCLUSION}

The present study asserted that the in-service training program was effective as teachers successfully integrated the MALL vocabulary learning applications in their instruction. This created a supportive and collaborative environment that enabled students to acquire vocabulary effectively and to overcome the difficulties and challenges associated with the traditional method of teaching vocabulary in which students were obliged to memorize long lists of isolated words without a proper technological assistance.

Based on the obtained results of the present study, educational policy makers are recommended to (1) tailor effective in-service training programs to guarantee the smooth and successful integration of MALL in vocabulary instruction, and (2) encourage teachers to integrate MALL applications in their teaching to foster students' vocabulary acquisition. Finally, investigating students' and teachers' attitudes towards the use of MALL vocabulary applications, using MALL to develop other language skills, investigating the impact of using MALL on affective aspects such as motivations and conducting a study to assess the effect of using each application separately are areas that need further research.

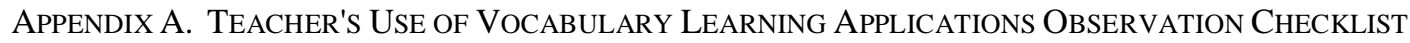

Instructor's name:

Date/Time:

\begin{tabular}{|l|l|l|l|l|l|l|}
\hline No. & Statements & $\begin{array}{l}\text { Strongly } \\
\text { disagree 1 }\end{array}$ & Disagree 2 & Neutral 3 & Agree 4 & $\begin{array}{l}\text { Strongly } \\
\text { Agree 5 }\end{array}$ \\
\hline 1 & $\begin{array}{l}\text { The teacher demonstrates a real understanding } \\
\text { of and mastery in using vocabulary learning } \\
\text { apps. }\end{array}$ & & & & \\
\hline 2 & $\begin{array}{l}\text { The teacher gives enough instructions to } \\
\text { facilitate students' use of vocabulary learning } \\
\text { apps. }\end{array}$ & & & & & \\
\hline 3 & $\begin{array}{l}\text { The teacher uses varied vocabulary learning } \\
\text { apps to suit the students' varied learning styles } \\
\text { and preferences. }\end{array}$ & & & & & \\
\hline 4 & $\begin{array}{l}\text { The teacher articulates clearly the objective } \\
\text { and significance of using vocabulary learning } \\
\text { apps. }\end{array}$ & & & & & \\
\hline 5 & $\begin{array}{l}\text { The teacher creates appropriate activities to } \\
\text { urge students to utilize vocabulary learning } \\
\text { applications to reinforce and extend their } \\
\text { vocabulary acquisition. }\end{array}$ & & & & & \\
\hline 6 & $\begin{array}{l}\text { The teacher encourages students' autonomy as } \\
\text { he requested the students to launch and } \\
\text { navigate within the apps independently. }\end{array}$ & & & & & \\
\hline 7 & $\begin{array}{l}\text { The teacher motivates students the use } \\
\text { vocabulary learning apps in and out language } \\
\text { classrooms. }\end{array}$ & & & & & \\
\hline 8 & $\begin{array}{l}\text { The teacher allows students to share } \\
\text { information with their peers. }\end{array}$ & $\begin{array}{l}\text { The teacher provides adequate feedback based } \\
\text { on students' use of vocabulary learning apps. }\end{array}$ & & & & \\
\hline 10 & $\begin{array}{l}\text { The teacher monitors and evaluates students' } \\
\text { vocabulary acquisition. }\end{array}$ & & & & & \\
\hline
\end{tabular}




\section{ApPENDiX B. Vocabulary ACQUisition TeST}

Read the following sentences carefully and choose the best answer from a, b, c, or d.

1. Fahad is probably the most person I've ever met. He is always in such a good mood.

$\begin{array}{lll}\text { a. aggressive } & \text { b. cheerful c. anxious } & d \text {. sensitive }\end{array}$

2. I won't be able to buy the mobile because I'm of money.

a. central b. tall c. short d. little

3. You can't buy that car. It's too
a. pra
c. reasonable
d. noisy

a. p

4. A tree is an evergreen forest tree.

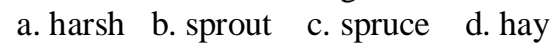

5. After a long flight, the plane

a. fell b. sank c. crashed d. landed

6. he travelled abroad for the first time at the

a. height b. weight c. length d. age of twenty.

7. study rocks and their history.

a. Teachers b. Doctors c. Engineers d. Geologists

8. Someone who is in __ owes money to someone else.

a. pay b. bank c. debt d. prison

9.Someone who writes for a newspaper is called a

a. journalist b. headmaster c. teacher d. champion

10. TV presenters _ sports stars on many favorite TV programs. a. test b. interview c. examine d. check

11. Normal human body __ is $37^{\circ} \mathrm{C}$.

a. height b. brain c. temperature d. pressure

12. My brother has the ___ to work 12 hours without stopping.

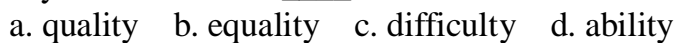

13. Ahmed has strong eyesight: he can see from a long a. distance b. reliance c. instance d. resistance

14. No liquids are served with meals because they interfere with a. suggestion b. digestion c. infection d. reaction

15. The human brain __ all senses.

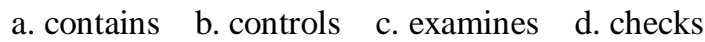

16. The astronaut, Neil Armstrong, went into a. atmosphere b. air c. space d. spade

17. Some people prefer living in a. modern b. rural c. fantastic d. fresh

18. Life has its and cons.

$\begin{array}{lll}\text { a. blues } & \text { b. pros } & \text { c. prose d. disadvantage }\end{array}$

19. The explosion made a ___ hole in the ground.

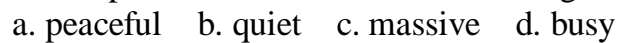

20. Japan has a ___ of about 130 million people. a. pollution b. popularity c. population d. people.

21. Sarah did not like the movie because the story was a. terrific $b$. bored c. exciting d. terrible

22. He always sits in the first __ in class because of his weak eyesight. a. line b. queue c. row d. verse

23. A/ An __ is someone whose job is to design buildings.

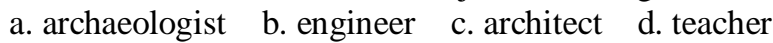

24. My father works for a/an which helps disabled children. a. information $\quad b$. intonation c. organization d. population

25. They found an old ship under the water which was full of

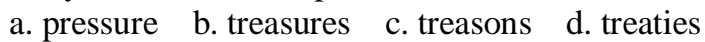

26. A/An _ protects a car driver in an accident. a. umbrella b. engine c. battery d. airbag

27. There are thousands of ___ which orbit the earth. $\begin{array}{lll}\text { a. moons } & \text { b. stars } & \text { c. satellites d. planes }\end{array}$

28. All living things need ___ in order to breathe and live.
a. oxygen b. oil
c. petrol
d. carbon

29. In forests, fires have a bad___ on plants and animals. a. affect b. affection c. effect d. effective 
30. When your mobile battery is empty, you have to it.

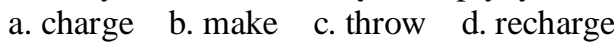

31. Wars and regional can lead to food shortage.
a. contacts
b. contrast
c. conflicts
d. concerts

32. Losing the final match was a to the fans of the team.

a. shake b. shocked c. shock d. chalk

33. __ means personal cleanliness.

a. Sanitation b. Dirt c. Hygiene d. Discovery

34. Last Tuesday, we went to the theatre to watch the new

a. poem b. play c. movie d. match

35. Shakespeare is considered one of the most famous
a. journalists
b. playwrights
c. players
d. actors

in England.

36. Helen Keller lost her sight. She was

a. dumb b. deaf c. mute d. blind

37. Parents should be with little children and slow learners.
a. cruel b. terrible
c. patient d. unkind

38. Our school team all the other teams in the competition.

a. earned b. won c. gained d. beat

40. Will you _t the floors tomorrow?

a. mop b. mow c. iron d. dust

41. If you have extra weight in your ___, you will pay for it in the customs.

$\begin{array}{llll}\text { a. luggage } & \text { b. binoculars } & c . \text { kit } & d \text {. sunglasses }\end{array}$

42. warming is causing a rise in ocean levels.

a. Universal b. Global c. World d. Regional

42. __ rain damages our lakes, rivers and forests as well as our buildings.

a. Fossil b. Solar c. Acid d. Global

43. Wind power has none of the of other forms of energy.

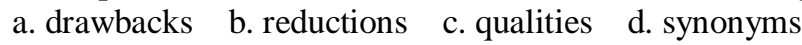

44. To craft something means to make it in a a. skilled b. bad c. very fast d. wrong way.

45. She decided to take the by the horns and tell her mother that she broke her mobile. a. cow b. sheep c. deer d. bull

46. Ahmed lives in a ___ flat near the center of town.

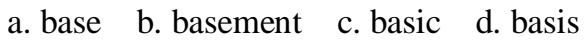

47. Old people often have

a. freckles b. dimples c. wrinkles d. sideburns

48. Your hobby is ___ if you love watching things grow.

a. gardening b. canoeing c. hiking d. cooking

49. souvenirs are often more expensive than manufactured ones.

a. Homemade b. Ancient c. Explosive d. Unspoiled

50. Most ancient castles had ___ to help keep out enemies.

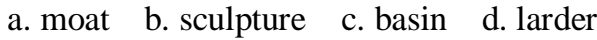

\section{REFERENCES}

[1] Al Malihi, J. (2015). Saudi EFL teachers' readiness and perceptions of young learners teaching at elementary schools. English Language Teaching, 8(2), 86-100.

[2] Al Sahli, A. (2014). The effect of using integrating online tools on first secondary Saudi students' vocabulary achievement in English. IOSR Journal of Research \& Method in Education, 4(6), 11-17. "doi.org/10.9790/7388-04631117".

[3] Al-Seghayer, K.(2011). English teaching in Saudi Arabia: Status, issues, and challenges. Riyadh, Saudi Arabia: Hala Print Co.

[4] Al Shehri, S. (2011). Context in our pockets: Mobile phones and social networking as tools of contextualizing language learning. 10th world conference on mobile and contextual learning. Beijing, China.

[5] Ally, M., Schafer, S., Cheung, B, McGreal, R., \& Tin, T. (2007). Use of mobile learning technology to train ESL adults. Paper included in the Proceedings of the $6^{\text {th }}$ Annual International Conference on Mobile Learning, Melbourne, Australia, pp. 7-12.

[6] Azabdaftari, B., \& Mozaheb, A. M. (2012). Comparing vocabulary learning of EFL learning by using two different strategies: Mobile language vs. flashcards. EUROCALL Review, 20(2),48-59.

[7] Baleghizadeh, S. \& Ashoori, A. (2011). The impact of two instruction techniques on EFL learners' vocabulary knowledge: Flash cards versus word lists. MEXTESOL Journal, 35(2), 70-82.

[8] Bazo, P., Rodriguez, R., \& Fumero, D. (2016). Vocabulary notebook: A digital solution to general and specific vocabulary learning problems in a CLIL context. In A. Pareja-Lora, C. Calle-Martinez, \& P. Rodriguez-Arancon (Eds.), New perspectives on teaching and working with languages in the digital era (pp. 269-279). Dublin: Research-publishing.net. "doi.org/10.14705/rpnet.2016.tislid2014.440". 
[9] Dashtestani, R. (2014). Computer literacy of Iranian teachers of English as a foreign language: Challenges and obstacles. International Journal of Pedagogies and Learning, 9(1), 87-100. "doi.org/10.1080/18334105.2014.11082022".

[10] Davie, N. \& Hilber, T. (2015). Mobile-Assisted language learning: Student attitudes to using smartphones to learn English vocabulary. Paper presented at the International Association for Development of the Information Society (IADIS) International Conference on Mobile Learning (11th, Madeira, Portugal, Mar 14-16. pp.70-78).

[11] Dehaan, J., Reed, W. M., \& Kuwada, K. (2010). The effect of interactivity with a music video game on second language vocabulary recall. Language Learning \& Technology, 14(2), 74-94.

[12] Deng, Q., \& Trainin, G. (2015). Learning vocabulary with apps: From theory to practice. The Nebraska Educator, 2, 49-69

[13] Dizon, G. (2016). Quizlet in the EFL classroom: Enhancing academic vocabulary acquisition of Japanese university students. Teaching English with Technology, 16(2), 40-56.

[14] Djoub, Z. (2016). Mobile technology and learner autonomy in language learning. In P. Zaphiris \& C. Sieng Ang (Eds.), Human-Computer Interaction: Concepts, methodologies, tools, and applications (291-309). Information Science Reference Hershey. New York.

[15] Ebrahimzadeh, M. (2017). Readers, players, and watchers: EFL students' vocabulary acquisition through digital video games. English Language Teaching, 10(2), 1-18. "doi.org/10.5539/elt.v10n2p1".

[16] Fisher, M. \& Baird, D. (2007). Making m-learning work, utilizing mobile technology for active exploration, collaboration, assessment, and reflection in higher education. Journal of Educational Technology Systems, 35(1), 3-30. "doi.org/10.2190/4t10-rx04-113n-8858".

[17] Gardner, H. \& Davis, K. (2013). The app generation. London: Yale University Press.

[18] Gee, J.P. (2003). What video games have to teach us about learning and literacy. New York, NY: Palgrave Macmillan.

[19] Hashemi, M. \& Abbasi, M. (2013). The impact/s of using mobile phone on English language vocabulary retention. International Research Journal of Applied and Basic Sciences, 4(3), 541-547.

[20] Hitosugi, C. I., Schmidt, M. \& Hayashi, K. (2014). Digital game-based learning (DGBL) in the L2 classroom: The impact of the UN's off-the-shelf videogame, Food Force, on learner affect and vocabulary retention. CALICO Journal, 31(1), 19-39. "doi.org/10.11139/cj.31.1.19-39".

[21] Hockly, N. (2013). Mobile learning. ELT Journal, 76, 80-84. "doi.org/10.1093/elt/ccs064".

[22] Khrisat, A. \& Mahmoud, S. (2013). Integrating mobile phones into the EFL foundation year classroom in King Abdul-Aziz University/KSA: Effects on achievement in general English and students' attitudes. English Language Teaching, 6(8),162- 174. "doi.org/10.5539/elt.v6n8p162".

[23] Koshman, S. (2011). iSchool agenda: Mobile context research and teaching. In Proceedings of the iConference 11. Seattle, USA, pp. 211-216. "doi.org/10.1145/1940761.1940790".

[24] Kuznekoff, J. \& Titsworth, S. (2013). The impact of mobile phone usage on student learning. Communication Education, 62(3). 233-252. "doi.org/10.1080/03634523.2013.767917".

[25] Larsen-Freeman, D. \& Anderson, M. (2011). Techniques and principles in language teaching. Oxford: Oxford University Press.

[26] Laufer, B. (2003). Vocabular acquisition in a second language: Do learners really acquire most vocabulary by reading? Some empirical evidence. Canadian Modern Language Review, 59(4), 567-587. "doi.org/10.3138/cmlr.59.4.567".

[27] Lomine, L. \& Buckhingham, C. (2009). M-learning: Texting (SMS) as a teaching \& learning tool in higher arts education. ELIA Teachers' Academy, Sofia.

[28] Macaro, E. (2005). Teaching and learning a second language: A guide to recent research and its applications. New York, NY: Continuum.

[29] McLean, S., Hogg, N., \& Rush, T. W. (2013). Vocabulary learning through an online computerized flashcard site. The JALT CALL Journal, 9(1), 79-98.

[30] Mishra, P. \& Koehler, M.J. (2006). Technological pedagogical content knowledge: A framework for teacher knowledge. Teacher College Record, 108(6), 1017-1054. "doi.org/10.1111/j.1467-9620.2006.00684.x".

[31] Nam, J. (2010). Linking research and practice: Effective strategies for teaching vocabulary in the ESL classroom. TESL Canada Journal/ Revue TESL de Canada, 28(1),127-135. "doi.org/10.18806/tesl.v28i1.1064".

[32] Nation, P. (2001). Learning vocabulary in another language. Cambridge, UK: Cambridge University Press.

[33] Norazah, N., Embi, M., \& Melor, Y. (2010). Mobile learning framework for lifelong learning. Procedia-Social and Behavioral Sciences, 7, 130-138. "doi.org/10.1016/j.sbspro.2010.10.019".

[34] Pachler, N. (2010). Mobile learning: Structures, agency, practices. Boston, MA: Springer Verlag.

[35] Passey, D. (2010). Mobile learning in school contexts: Can teachers alone make it happen? IEEE Transactions on Learning Technologies: Special issue on mobile and ubiquitous technologies for learning, 3(1), 68-81. "doi.org/10.1109/tlt.2009.47".

[36] Quizlet. (2014). About Quizlet. Quizlet. Retrieved May 15, 2016 from http://quizlet.com/mission.

[37] Reinhardt, J. \& Sykes, J. M. (2012). Conceptualizing digital game-mediated L2 learning and pedagogy: Game-enhanced and game-based research and practice. In H. Reinders (Ed.). Digital games in language learning and teaching (pp.32-49). New York, NY: Palgrave Macmillan. "doi.org/10.1057/9781137005267_3".

[38] Romero, R., Zarraonandia, T., Aedo, I. \& Diaz, P. (2010). Designing usable educational material for English courses supported by mobile devices. Springer. "doi.org/10.1007/978-3-642-16607-5_25".

[39] Saeidi, M. \& Mozaheb, M. (2012). Comparing vocabulary learning of EFL learners by using two different strategies (mobile learning vs. flashcards). International Journal of Mobile Learning and Organization,6 (3/4), 303-315. "doi.org/10.1504/ijmlo.2012.050050".

[40] Saran, M., Cagiltay, K., \& Saferoglu, G. (2008). Use of mobile phones in language learning: Developing effective instructional materials. Paper presented at the Fifth IEEE International Conference on Wireless, Mobile, and Ubiquitous Technology in Education (Mar 23 - 26, pp.39-43).

[41] Sharples, M., Taylor, J., \& Vavoula, G. (2005). Towards a theory of mobile learning. Proceedings of $m$ Learn, 1(1), 1-9. 
[42] Silverman, R. \& Hines, S. (2009). The effects of multimedia-enhanced instruction of the vocabulary of English-language learners and non-English-language learners in Pre-kindergarten through second grade. Journal of Educational Psychology, 101(2), 305-314. "doi.org/10.1037/a0014217".

[43] Suneetha, Y. (2013). MALL (mobile assisted language learning): A paradise for English language learners. International Journal of English Language \& Translation Studies, 1(2), 91-99.

[44] Tsai, C. W., \& Fan, Y. T. (2013). Research trends in game-based learning research in online learning environments: A review of studies published in SSCI-indexed journals from 2003 to 2012. British Journal of Educational Technology, 44(5), 115-119. "doi.org/10.1111/bjet.12031".

[45] Valarmathi, K. E. (2011). Mobile assisted language learning. Journal of Technology for ELT, 2(2), 1-8.

[46] Vota, W. (2011). Tablets are good, content is better, and teachers are the best educational ICT investment. Tablet Computers in Education. Retrieved in Oct. 2016 from http://edutechdebate.org/tablet-computers-in-education/tablets-are-good-content-isbetter-and-teachers-are-the-best-educational-ict-investment.

[47] Walters, J. (2009). The effect of keeping vocabulary notebooks on vocabulary acquisition. Language Teaching Research, 13(4), 403-423. "doi.org/10.1177/1362168809341509".

[48] Weinberger, S. (2011). Teacher mate: Individualized, teacher-assisted instruction. Low-cost ICT devices. Exploring ICT and learning in developing countries. Retrieved in Nov. 2016 from https://edutechdebate.org/low-cost-ict-devices/teachermateindividualized-teacher-assisted-instruction.

[49] Zaki, A. \& Yunus, M. (2015). Potential of mobile learning in teaching of ESL academic writing. English Language Teaching, 8(6), 11-19. "doi.org/10.5539/elt.v8n6p11"

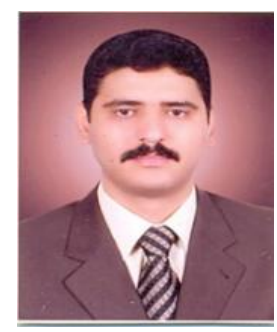

Mohamed A. Kassem is a faculty member at the Dept. of Curriculum and Teaching Methods, College of Education in the New Valley, Assiut University, Egypt. He earned his PhD in TEFL as a result of a joined supervision program between Assiut University, Egypt and Georgia State University, USA in 2011. His major areas of research are writing instruction, integrating MALL in EFL teaching, vocabulary acquisition and EFL teacher education. 